\title{
Measurement of Urea and Creatinine as a Marker of Renal Function in Type 2 Diabetes Mellitus in Patients with Good Glycemic Control and Poor Glycemic Control
}

\author{
Dr. Raisa Faheem, Dr. Tahmeen Jameel*, Dr. Raiyan Ali Afrooz, Dr. Syed Junaid Ahmed
}

Deccan college of Medical sciences, Hyderabad, India

\author{
DOI: $10.36348 /$ SIJB.2019.v02i09.002 $\quad$ | Received: 07.09.2019| Accepted: 16.09 .2019 | Published: 29.09 .2019 \\ *Corresponding author: Dr. Tahmeen Jameel
}

\section{Abstract}

Diabetes is a common cause of end stage renal disease and approximately 20 to $30 \%$ of all diabetics will develop nephropathy. Diabetic nephropathy is characterised by abnormal renal function with reduction of glomerular filtration and rise in the level of Serum Urea and Creatinine. The study was conducted at Princess Esra Hospital, Deccan College of Medical Sciences. Patients with Dm in the age group 35 Yrs - 55 Yrs and controls also of the same age group Glycosylated Haemoglobin ( $\mathrm{Hb}$ A1C) was done to categorise patients into two groups. Patients with good glycemic control having $\mathrm{HbA} 1 \mathrm{c}<6-7 \%$, Studies have demonstrated that the complications of diabetes can be delayed or preventedif HbA1c can be kept between 6-7\%. The other group of patients were having poor glycemic control with HbA1c above $8 \%$. The following parameters were included in the study FBS, PLBS, HbA1cm Urea and Creatinine. These parameters were estimated in normal (controls) and diabetics (with good glycemic control) and diabetics (with poor glycemic control). It was found that the blood sugar, blood urea and serum creatinine levels were significantly higher in diabetic patients with poor glycemic control compared to diabetic patients with good glycemic control. Strong relationship of blood urea and serum creatinine levels was found with blood sugar and HbA1c levels. Blood urea, serum creatinine blood sugar along with HbA1c would be helpful to monitor the diabetes patients to assess renal function.

Keywords: Fasting blood sugar (FBS) Post lunch blood sugar (PLBS), Glycosylated Haemoglobin HbA1c.

Copyright @ 2019: This is an open-access article distributed under the terms of the Creative Commons Attribution license which permits unrestricted use, distribution, and reproduction in any medium for non-commercial use (NonCommercial, or CC-BY-NC) provided the original author and source are credited.

\section{INTRODUCTION}

Diabetes mellitus is characterized by chronic hyperglycemia due to derangement in Carbohydrate, fat and protein metabolism. The level of morbidity and mortality due to diabetes and its potential complications are enormous. (Kaveeshwar SA 1)[1]. Diabetes mellitus is associated with absolute or relative deficiencies in insulin secretion, insulin action or both (Kanwar G [2]). Less glycemic control, sedentary life style, dietary modifications, genetic mutations, smoking, high blood pressure, elevated cholesterol levels, obesity and lack of regular exercise are considered to be risk factors that have led to a dramatic increase in the incidence of diabetes. (American Diabes Association)[3], (Caramori LM) [4], (Elfaki ME)[5]. Clinically diabetic nephropathy is evidenced by proteinuria, decline in glomerular filtration rate (GFR) hypertension and has high risk of cardiovascular morbidity and mortality (Shlomo M) [6]. In diabetic nephropathy, biomarkers serum urea and creatinine are known to be raised with hyperglycemia in uncontrolled diabetics and usually correlates with severity of kidney damage. Measurement of Serum Urea and Creatinine are easily available tests for this purpose which can assist in detection and prevention diabetic kidney disease at an early stage and can limit the progression to end stage renal disease (ESRD) (Shlomo $\mathrm{m}$ ) (Zimmet) [7]. The amount of Creatinine excreted is proportional to total Creatine Phosphate content of the body, in turn the muscle mass. Serum Creatinine correlates quite well with the percent of the body that is skeletal muscle. It is filtered by the glomerulus, and a small amount is also secreted into the glomerular filtrate by the proximal tubule.

Glycosylation of tissue proteins may contribute to diabetic nephropathy apart from other micro vascular complications. In diabetes mellitus, hyperglycaemia causes the excess of glucose to combine with free amino acids on circulating or tissue protein. This non-enzymatic process initially forms reversible early glycosylation products and later irreversible advanced glycosylation end products via an 
A madori rearrangement. The tissue accumulation of Advanced glycosylation end products by cross linking with collagen, can contribute to the associated renal and micro vascular complications (Evans)[8]. Good glycemic control can reduce the incidence of diabetic nephropathy. The earliest detectable abnormality of nephropathy is micro albuminuria followed by decrease in glomerular filtration rate (GFR) and increase in Serum Creatinine concentration (Gonzalez Suarez ML) [9]. The present study was aimed to quantitatively estimate the amount of blood urea, Serum Creatinine in patients with Type 2 Diabetes mellitus and comparing it between patients with good glycemic control and poor glycemic control based on $\mathrm{HbAlc}$ result.

\section{MATERIALS AND METHOD}

The present study was conducted in the department of Biochemistry, Princess Esra Hospital, and Deccan College of Medial Sciences. A total of 40 diabetic patients and 40 normal control subjects with normal renal function tests and normal Random Blood Glucose were selected as controls. The study included both sexes male $\&$ female.

\section{The following parameters were done}

- FBS, PLBS sample was collected in Grey Cap Vaccutainer containing $\mathrm{NaF} / \mathrm{Na}$ 2EDTA.

- Urea and Creatinine sample was collected in yellow cap vaccutainer with clot activator and gel for serum separation.

- Glycosylated Haemoglobin (HbA1c) sample was collected in lavender colour cap vaccutainer with K2 EDTA.

\section{Method}

- Blood glucose (FBS, PLBS) was done in an automated Analyzer Cobas c 311 by GlucoseOxidase and Peroxidase (GOD - POD) method.

- Glycosylated Hemoglohin (HBA1c) done in a semi automated Analyzer stat fax (Direct with Calibrator) by Immunoturbidimetry with Beacon reagent.

- Urea in an automated Analyzer Cobas c 311 by Urease, Glutamate Dehydrogenase method.

- Creatinine in an automated Analyzer cobas c 311 by modified Jaffes Kinetic Method.

Table-1: Reference ranges

\begin{tabular}{|l|l|l|l|}
\hline S. No. & Parameter & Units & Reference range \\
\hline 1. & FBS & $\mathrm{mg} / \mathrm{dl}$ & $70-100$ \\
\hline 2. & PLBS & $\mathrm{mg} / \mathrm{dl}$ & $<150$ \\
\hline 3. & HbAlc & $\%$ & $<6 \%$ normal \\
& & & $6 \%-7.0 \%$ good glycaemic control \\
& & & $\begin{array}{l}7.1 \%-8.2 \% \text { fair }(\text { acceptable glycaemic control) } \\
>8.2 \% \text { poor glycaemic control }\end{array}$ \\
& & & $15-40$ \\
\hline 4. & Urea & $\mathrm{mg} / \mathrm{dl}$ & $\begin{array}{l}0.5-1.1 \text { (Females) } \\
0.7-1.3 \text { (males) }\end{array}$ \\
\hline 5. & Creatinine & $\mathrm{mg} / \mathrm{dl}$ & \\
& & &
\end{tabular}

Table-2:

Group I: Normal control

Group II: Diabetes with good glycaemic control HbA1c between 6-7\%

Group III: Diabetes with poor glycaemic control HbA1c $>8.2 \%$

Comparison among study groups for FBS, PLBS and HbA1c

Table-2

\begin{tabular}{|c|l|l|l|}
\hline Parameter & Groups & Mean+SD & $\begin{array}{l}\text { Analysis of various (P Value } \\
\text { (ANOVA TEST) }\end{array}$ \\
\hline \multirow{3}{*}{ FBS } & Group I (40) & $82.16 \pm 5.40$ & \multirow{3}{*}{$<0.001$} \\
\cline { 2 - 3 } & Group II (40) & $116 \pm 7.24$ & \\
\cline { 2 - 3 } & Group III (40) & $179 \pm 33.22$ & \multirow{3}{*}{$<0.001$} \\
\hline \multirow{3}{*}{ PLBS } & Group I & $128.22 \pm 7.11$ & \\
\cline { 2 - 3 } & Group II & $149.36 \pm 8.20$ & \\
\cline { 2 - 3 } & Group III & $266.12+54.33$ & \\
\hline \multirow{3}{*}{ HbA1c } & Group I & $5.13 \pm 0.26$ & \\
\cline { 2 - 3 } & Group II & $6.87 \pm 0.44$ & 0.037 \\
\cline { 2 - 3 } & Group III & & \\
\hline
\end{tabular}


Table-3: Comparison among study for Urea \& Serum Creatinine

\begin{tabular}{|c|l|l|l|}
\hline Parameter & Groups & Mean + SD & Analysis of various (P Value (ANOVA TEST) \\
\hline \multirow{4}{*}{ Urea } & Group I & $26.41+3.48$ & \multirow{3}{*}{$<0.001$} \\
\cline { 2 - 3 } & Group II & $49.86 \pm 13.39$ & \\
\cline { 2 - 3 } & Group III & $68.76+16.21$ & \\
\hline \multirow{3}{*}{ PLBS } & Group I & $0.81+0.17$ & \multirow{3}{*}{$<0.001$} \\
\cline { 2 - 3 } & Group II & $1.71 \pm 0.77$ & \\
\cline { 2 - 3 } & Group III & $2.721 \pm 0.80$ & \\
\hline
\end{tabular}

\section{RESULT \& DISUCSSION}

In the present study, a total of $n=40$ diabetic subject including both males \& females and same $n=$ 40 controls were selected and studied. The diabetic patients were divided into 2 groups, group II with good glycaemic control having HbA1c $<7$ and group III with poor glycaemic control having HbA1c $>8.2$. The study was undertaken to study the levels of Serum Creatinine and Urea in Diabetes mellitus with good glycaemic control and poor glycaemic control.

Hyperglycaemia (poor glycemic control) is a characteristic feature of diabetes mellitus, is a fact well accepted by many (Americal Diabetes Association) [10]. In this study, there was a statistical significant increase in serum creatinine and Urea level in Diabetes with poor glycaemic control in comparision with a marginal increase in serum creatinine level and Urea level in diabetes with good glycemic compared with normal controls.

This shows that poorly controlled blood sugar levels would cause increase in the serum urea levels and thus increase the chances of the patient suffering from diabetic nephropathy. This corroborates with the findings of other studies which reported that hyperglycemia is one of the major cause of progressive renal damage (Shlomo), (Shrestha) [11]. The results of ouw study is in accordance with various studies which showed that raised serum creatinine and urea levels in diabetic patients may indicate a pre renal problem (Aldler Al) [12]. Serum levels of urea and creatinine can be used as useful prognostic markers and predictors of renal damage in diabetic patients (Alder $\mathrm{Al}$ ). Effective control of blood sugar levels can stop progression to diabetic nephropathy and thus remarkably reduce the morbidity and mortality associated with this metabolic disorder.

Estimation of Renal function tests is simple, reliable, economic and sensitive that can now be considered as an adjunct in the management and long duration treatment of type 2 diabetes mellitus disorder (Al mamory al Saleh Al)[13].

\section{REFERENCES}

1. Kaveeshwar, S. A., \& Cornwall, J. (2014). The current state of diabetes mellitus in India. The Australasian medical journal, 7(1), 45.
2. Kanwar, G., Jain, N., Sharma, N., Shekhawat, M., Ahmed, J., \& Kabra, R. (2015). Significance of serum urea and creatinine levels in type 2 diabetic patients. IOSR J Dent Med Sci, 14(8), 65-7.

3. Kahn, R. (2003). American Diabetes Association: diagnosis and classification of diabetes mellitus. Diabetic Care, 26(1), 3160-3167.

4. Caramori LM, Fioretto P, Mauer M. Enhancing the Predictive Value of Urinary Albumin for Diabetic Nephropathy. JASN.2006; 17:339-352.

5. Elfaki, E. M., Raheem, E. M. A., \& Ahmed, S. E. (2014). Evaluation of Lipid Metabolism among Sudanese Patients with Type 2 Diabetes Mellitus. International Journal of Pure and Applied Sciences and Technology, 23(1), 28.

6. Shlomo, M., Polonsky, K.S., Larsen, P.R., Kronenberg, H.M. (2011). Diabetes Mellitus, Willams textbook of endocrinology, $12^{\text {th }}$ Ed. Philadelphia: Elsevier/Saunders, 1371-1435.

7. Zimmet, P., Alberti, K.G, Shaw, J. (2001). Global and social implications of the diabetes. Nature 2001; 414:782-7.

8. Evans, T.C., Capell, P. (2000). Diabetic nephropathy. Clin Diabetes. 2000; 18(1). Available from:

http://www.journal.diabetes.org/clinicaldiabetes/v1 8n12000/Pg7.htm. [Last accessed on 2017 Mar24].

9. Gonzalez, Saurex, M.L, Thomas, D.B., Barisoni, L., Fornoni, A. (2013).Diabetic nephropathy: Is it time yet for routine kidney biopsy? World J Diabetes, 4(6):245-55.

10. American Diabetes Association.(2009). Diagnosis and classification of diabetes mellitus. Diabetes Care, 32 Suppl 1:S63-7.

11. Shrestha, S., Gyawali, P., Shrestha, R., Poudel, B., \& Sigdel, M. (2008). Serum urea and creatinine in diabetic and non-diabetic subjects. Journal of Nepal Association for Medical Laboratory Sciences $P, 11,12$.

12. Adler, A. I., Stevens, R. J., Manley, S. E., Bilous, R. W., Cull, C. A., Holman, R. R., \& UKPDS Group. (2003). Development and progression of nephropathy in type 2 diabetes: the United Kingdom Prospective Diabetes Study (UKPDS 64). Kidney international, 63(1), 225-232.

13. Almamory, I. A. A. S., \& Tsahel, H. (2014). Detection level of urea, sugar, creatinine and hematology in patients of diabetic mellitus type II. Journal of Medicine and Medical Sciences, 5(7), 154-156. 